\title{
Role of percutaneous nonvascular Interventional Radiology treatments in musculoskeletal lesions
}

\author{
Deep Narayan Srivastava \\ Department of Radiodiagnosis, \\ All-India Institute of Medical Sciences, New Delhi.
}

\section{SUMMARY}

Many new, minimally invasive interventional radiology procedures are now viable alternatives to traditional invasive therapy. These interventional radiological procedures can be performed in the outpatient setting and the overall cost to the patient may be less in the long run. Radiofrequency and Laser ablation techniques are now widely used and rapidly expanding technologies in the interventional radiology used in the treatment of tumours, varicose vein and lumbar disc treatment. Similarly percutaneous vertebroplasty (PVP) is used in the treatment of spinal lesions and osteoporotic vertebral collapse. The knowledge of these procedures is vital as medicine moves into minimally invasive procedures with targeted treatments as these procedures offer less risk, less pain and less recovery time compared to various surgical procedures.

In this presentation I would like to present my work related to percutaneous vertebroplasty (PVP) in spinal lesions, percutaneous Laser disc decompression (PLDD) in the treatment of chronic discogenic low back pain and percutaneous radiofrequency ablation (RFA) in musculoskeletal lesions. The technique, results and long term outcomes of these newer procedures will be discussed.

Key words : Interventional radiology, MSK, Vertebroplasty, PLDD, RFA, arthrography.

Correspondence : Dr. Deep Narayan Srivastava, Professor, Deptt. of Radio-diagnosis, All-India Institute of Medical Sciences, New Delhi-110029. E mail: drdeepsrivastava@rediffmail.com, M: 9899245764.

ACHANTA LAKSHMIPATI ORATION delivered during NAMSCON 2015 at the AllIndia Institute of Medical Sciences, Patna. 


\section{INTRODUCTION}

Interventional radiological techniques are useful in the diagnosis and treatment of some of the musculoskeletal pathologies. Among these are diagnostic and therapeutic treatments of back pain using discography, nerve root injections, percutaneous vertebroplasty (PVP) and percutaneous laser disc decompression (PLDD). Similarly arthrography in conjunction with a post arthrogram MRI is used in the diagnosis of joint pathologies.

Percutaneous technique like biopsy is used for diagnosis of musculoskeletal lesions and radiofrequency or laser ablation is used in the treatment of these lesions. These techniques are as follows:

\section{Interventional spinal procedures :}

Low back pain (LBP) represents the second cause for a medical consultation in primary care setting and a leading cause of disability worldwide (1). It is a disorder with many possible etiologies, occurring in every groups of the population, and with several definitions. Severe back pain can cause serious disability as it can impair mobility and affect quality of life.

In the elderly population, the common causes include osteoporotic collapse, metastatic vertebral lesions and multiple myeloma. Even younger patients can have significant back pain due to vertebral lesions such as haemangiomas, which may cause backache without reduction in the vertebral body height. Although involutional osteoporosis from ageing is the most common cause of osteoporosis and osteoporosis related fractures, certain medical conditions like cushing's syndrome, exogenous steroid administration, surgical procedures and drugs are associated with the development of osteoporosis in $20 \%$ of women and $40 \%$ of men (2).

Disc herniation is also an important cause of low back pain that generally affects elderly people and is now increasingly affecting younger people by virtue of misdirected kinetics (3). In recent years, several minimally invasive interventional radiology procedures under local anaesthesia have been developed for the treatment of low back pain due to various aforesaid causes. These include:

- $\quad$ Percutaneous vertebroplasty (PVP)

- Percutaneous treatment of disc herniation

[laser disc decompression (PLDD) \& ozone therapy]

\section{Percutaneous Vertebroplasty (PVP):}

Percutaneous vertebroplasty is a well-accepted interventional procedure for the treatment of painful vertebral lesions. The technique first introduced in 1984 by Deramond et al (4) in a patient with haemangioma of a cervical vertebra not responding to conventional measures to obtain pain relief, have been subsequently used for the treatment of numerous lesions causing back pain associated with vertebral involvement like osteoporotic vertebral collapse, metastatic disease, multiple myeloma and symptomatic vertebral haemangiomas. 


\section{Technique:}

The procedure consists of instilling acrylic bone cement into the affected vertebra through a bone biopsy needle by a percutaneous approach. The cement consists of polymethylmethacrylate (PMMA) is obtained by mixing liquid monomer to the powdered polymer, which is mixed just before injection. The cement is injected into the lesion after needle placement, under fluoroscopic control (5). The cement polymerises and subsequently sets, affording support to the vertebra (Fig. 1). The steps of the procedure are:

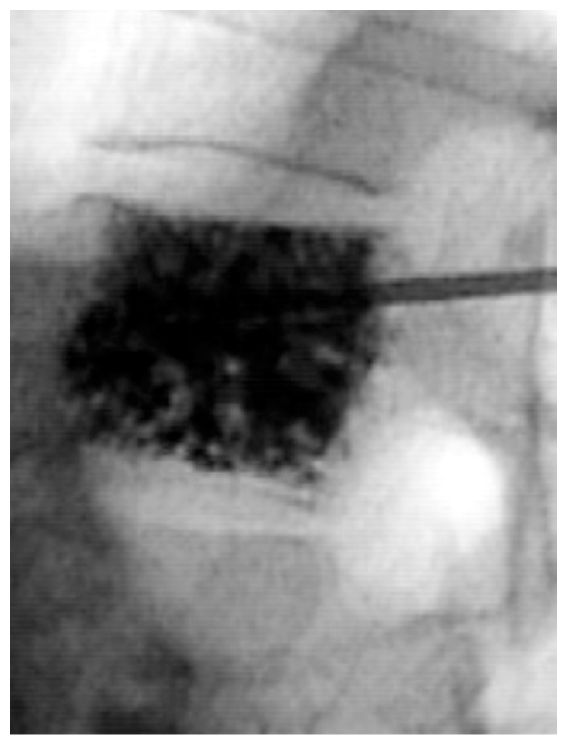

Fig. 1: 30 yr female with symptomatic D12 vertebral haemangioma, successfully treated with percutaneous vertebroplasty using polymethylmethacrylate (PMMA) bone cement. The vertebroplasty needle is seen in position with injected bone cement.
I. Patient is placed in prone position on angiography/fluoroscopy table.

II. The procedure is performed under sterile conditions. The skin over the centre of the pedicle is anaesthetised with local anaesthesia. A small skin incision is made and bone biopsy needle is positioned with its tip in the centre of the mid point of the pedicle.

III. The needle is advanced under AP and Lat fluoroscopy till the junction of the anterior and middle third of the vertebral body. Approximately 6 ml PMMA cement is injected.

IV. Patient is placed in supine position for few hours after the procedure and is discharged after 6 hours.

Results :

Vertebroplasty results in relief of pain with decrease in analgesic use. It provides strength so prevents further collapse and pain relief by coagulating the tissue. The relief is obtained irrespective of the cause of pain, and is long lasting (5).

It is a safe procedure with a high efficacy in pain relief, and improvement of quality of life in patients with diverse types of vertebral metastases from breast cancer (6). In a study it has also been used successfully as a first line treatment in patients with non-osteoporotic compression fractures and can decrease pain, increase mobility and decrease narcotic administration (7).

\section{Complications :}

The incidence of complications is 
less though various complications associated with the procedure are as follows:

1. Cement leaks outside the vertebra are mostly inconsequential, but can cause local or radicular pain, neurological damage and pulmonary embolism. The major leaks of cement were seen into the spinal canal, intravasation into veins, neural foramens leak and leak into disc space. Acrylic cement of polymethylmethacrylate injected into the vertebral body can leak into the paravertebral venous system and reach the pulmonary artery via the azygos vein leading to a cement pulmonary embolism (8).

2. Inaccurate needle placement can injure nerve root or spinal cord.

3. Pain exacerbation may occur due to substantial cement leaks.

4. Rarely puncture site infection and bleeding may occur.

Laredo et al (9) reviewed the various complication rates from numerous studies and reported total complication rates for malignant cases $38 \%$ to $72.5 \%$ and in osteoporosis $30 \%$ to $65 \%$.

\section{Future Directions :}

Although vertebroplasty can give considerable pain relief, it is not very useful in vertebral body height restoration. Another technique called kyphoplasty (10) involves the inflation of a bone tamp within the vertebral body to restore the height of the vertebra, and subsequently placing bone cement for augmentation of strength.

Gangi A (11) described a dedicated therapeutic vertebroplasty technique that uses newly designed instruments, acrylic cement, and dual guidance with ultrasonography and computed tomography for pain control in patients with bone failure. They performed PVP procedures in patients with severe osteoporosis, vertebral tumors, and symptomatic haemangiomas and satisfactory results were obtained in osteoporosis $(78 \%)$ in vertebral tumors $(83 \%)$ and in haemangiomas $(73 \%)$.

Percutaneous vertebral augmentation remains a proven medically appropriate therapy for treatment of painful vertebral compression fractures refractory to non-operative medical therapy and for vertebrae weakened by neoplasia when performed for the medical indications outlined in the published standards (12).

\section{Percutaneous Treatment of disc Herniation :}

Treatment of herniated disc has evolved from open surgical techniques to minimally invasive or micro therapeutic procedures under local anaesthesia. The long term outcome, the complications and the suboptimal results that may accompany open disc surgery have led to the early development of other treatment techniques that would avoid a surgical approach through the spinal canal. These include percutaneous laser disc 
decompression (PLDD), percutaneous ozone therapy and percutaneous/ endoscopic nucleotomy.

In PLDD, laser energy is delivered into nucleus pulposus by laser fibre, through a needle. The aim of PLDD is to vaporize a small portion of the nucleus pulposus. The ablation of this small volume results in reduction of intradiscal pressure, thus reducing the disc herniation (3) (Fig. 2).

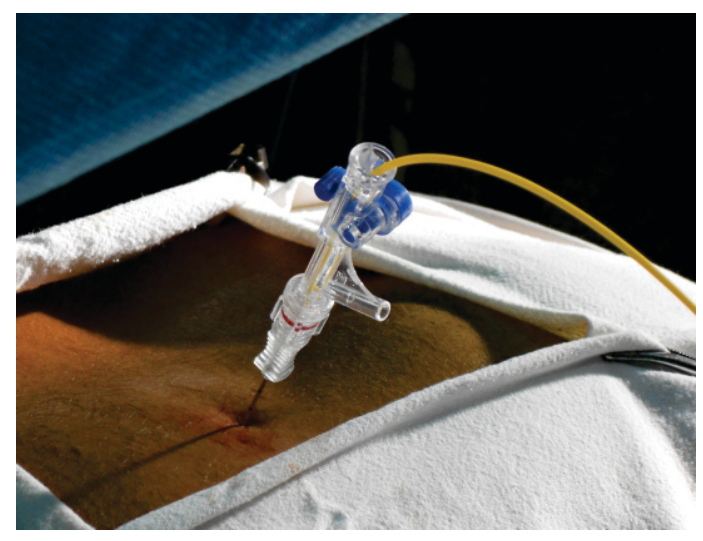

Fig. 2: Percutaneous laser treatment of herniated disc. A lumbar puncture needle is placed into the disc under fluoroscopy. After proper position of needle, optical fibre is advanced through the needle and laser energy is deposited.

In a recent study the feasibility, safety and efficacy of real time MR guidance and thermometry of PLDD was found to be feasible with complete remission of radicular pain in $21 \%$ of patients at six months follow-up assessment without any major complications (13).
The role of provocative discography prior to PLDD has been assessed and found to be useful. Discography is often carried out as the first step of an operative procedure such as chemonucleolysis, intradiscal radiofrequency or laser therapy or intradiscal injection of steroids or anaesthetics (14).

In percutaneous ozone treatment, mixture of ozone-oxygen gas is administered into nucleus pulposus through the needle. This mixture has a direct effect on the proteoglycans of the nucleus pulposus, resulting in release of water molecules and subsequent degeneration of matrix and reduction of volume (15) (Fig. 3).

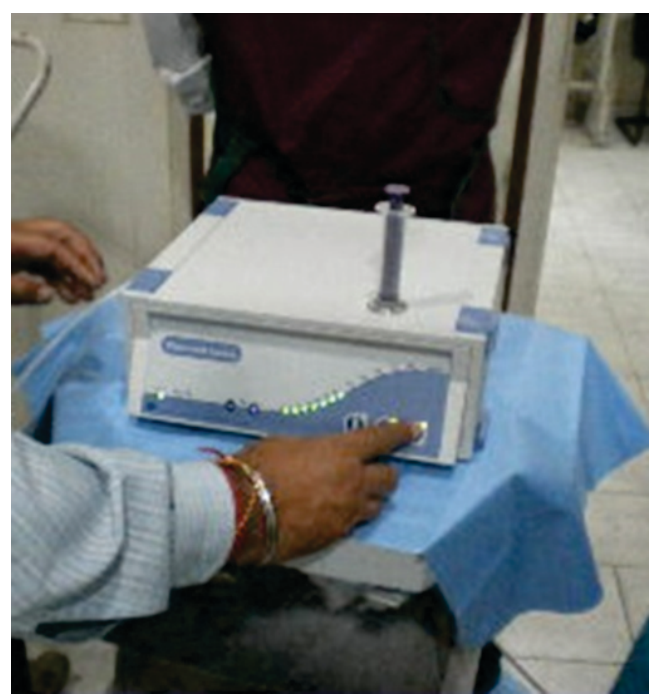

Fig. 3: Percutaneous ozone treatment of herniated disc. A lumbar puncture needle is placed into the disc under fluoroscopy and ozone gas is injected after preparing it from ozone generator machine. 
Both PLDD and percutaneous ozone therapy are not used for uncontained herniations or sequestered disc. In both the procedures, patient is positioned prone and using either fluoroscopy or CT guidance a proper lumbar puncture needle $(18-21 \mathrm{G})$ is inserted into the centre of disc. After proper position of the needle, for PLDD, an optical fibre is advanced through the needle and proper laser energy is given. For ozone treatment, approximately $4 \mathrm{ml}$ of ozone-oxygen mixture is injected with an ozone concentration of $27 \mu \mathrm{g} / \mathrm{ml}$ (16).

Arthrography in conjunction with a post arthrogram MRI :

Conventional arthrography used to be the procedure of choice in the evaluation of joints, however it has been replaced with CT and MR arthrography as these can additionally show internal structures of joints. CT or MR arthrography is now frequently used in the diagnosis and treatment of various joint diseases like shoulder, elbow, wrist, hip, knee and ankle $(17,18,19)$.

It is performed under fluoroscopic guidance using a 21 gauge lumbar puncture needle under aseptic precautions and after distending the joint with contrast, cross sectional imaging (CT or MR) is done (Fig. 4). It is useful in both adults and paediatric population (20).

\section{Percutaneous ablation of bone tumours:}

Percutaneous image guided tumor ablation with thermal energy source such as radiofrequency, laser or microwave energy is used in the treatment of both benign (osteoid osteoma, osteoblastoma, enchondroma etc.) and malignant (metastatic) lesions in place of surgery due to potentional benefits such as minimal invasiveness, reduced cost and morbidity $(21,22)$.
A

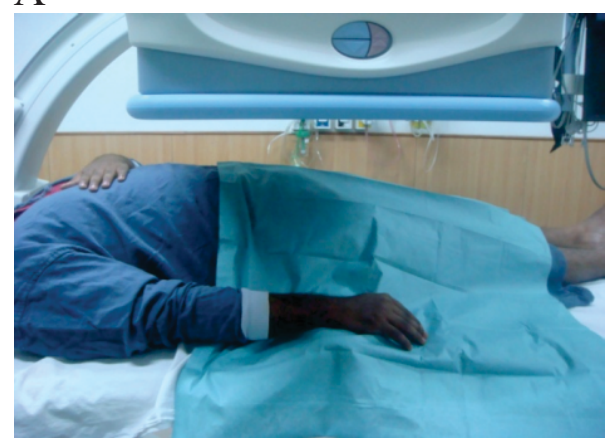

B



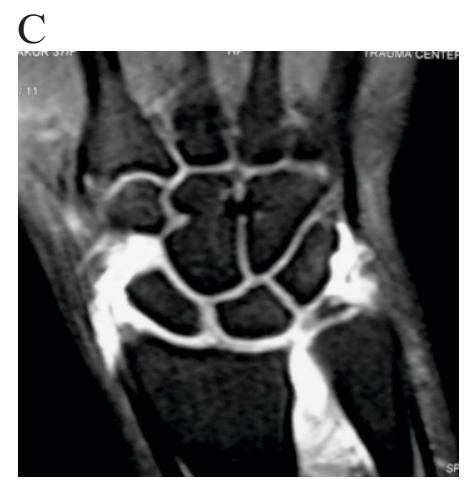

Fig. 4A to C: Arthrography in conjunction with a post arthrogram MRI of wrist in evaluation of triangular fibrocartilage complex (TFCC) Tears. A needle is placed into the joint under fluoroscopy (A). After proper position of needle, the joint is distended with contrast (B) and MR arthrogram is done. Coronal fat suppressed T1W MR arthrogram (C) is showing TFCC tear. 
A

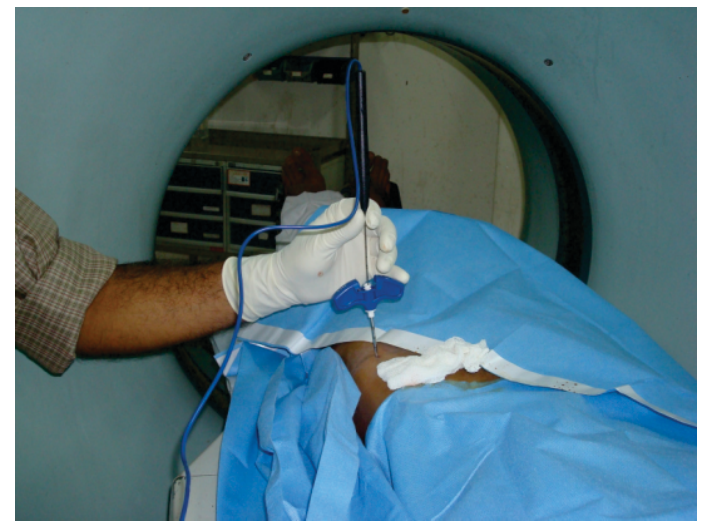

$\mathrm{B}$

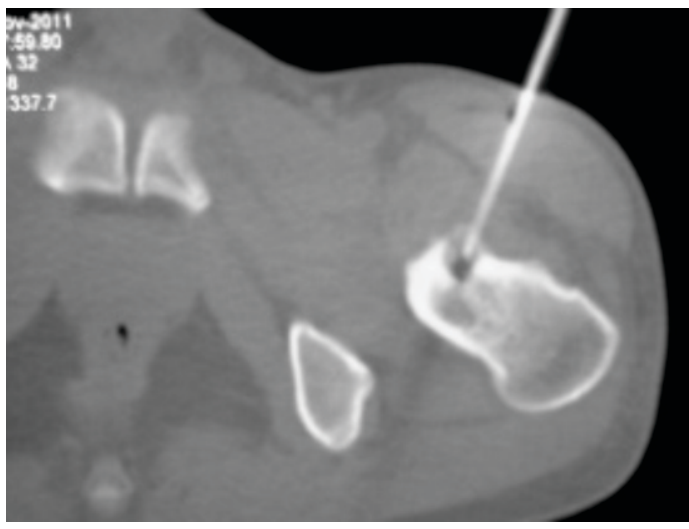

Fig. 5 A \& B: Percutaneous RF ablation of osteoid osteoma. After placement of bone biopsy needle into the lesion under $\mathrm{CT}$ guidance the stylet was withdrawn and the RF probe was introduced (A). Axial CT image at the time of procedure (B) showing tip of the biopsy needle in the lesion.

Osteoid osteoma is a benign but painful bone tumour, usually found in lower extremities of children and young adults and ablation is done for control of pain.

The procedure is performed with CT guidance under either general anaesthesia or conscious sedation. A proper bone biopsy needle is placed into the lesion with the help of a hammer or a drill. Radiofrequency probe or laser fibre is introduced through the cannula and proper energy is delivered for ablation (Fig. 5).

\section{Conclusion :}

Interventional radiology offers minimally invasive image guided therapy for a growing range of nonvascular diseases. Percutaneous image guided peritendinous injections of various drugs including platelet rich plasma (PRP) that contains various growth factors \& cytokines that stimulate healing of bone and soft tissues are now frequently used in sports related injuries $(23,24)$.

I believe that the future of musculoskeletal procedures is bright with promise. We will need to work hard and creatively to maintain collegial working relationships with other specialties. We must learn to address and satisfy the expectations that come with greater patient care responsibilities, and above all, we must support innovations that are in the best interest of our patients.

\section{Acknowledgments :}

The author thanks the students especially Dr. Muneer Essa and Dr. Vankatesh and clinical colleagues for their help, support and for many fruitful discussions. 


\section{REFERENCES :}

1. Izzo R, Popolizio T, D' Aprile P, Muto M (2015). Spinal pain. Eur $J$ RadiolFeb.13.

2. Jensen ME, Dion JE (2000). Percutaneous vertebroplasty in the treatment of osteoporotic compression fractures. Neuroimaging CAN 10: 547-568.

3. Gupta AK, Bodhey NK, Jayasree RS, et al. (2006). Percutaneous laser disc decompression: clinical experience at SCTIMST and long term follow up. Neurol India 54(2):164-167.

4. Galibert $\mathrm{P}$, Deramond $\mathrm{H}$, et al. (1987). Preliminary note on the treatment of vertebral angioma by percutaneous acrylic vertebroplasty. Neurochirurgie 33:166-168.

5. Barr JD, Barr MS, Lemley TJ, et al. (2000). Percutaneous vertebroplasty for pain relief and spinal stabilisation. Spine 25: 923-928.

6. Barragan-Campos HM, Le Faou AL, Rose M, et al. (2014). Percutaneous vertebroplasty in vertebral metastases from breast cancer: interest in terms of pain relief and quality of life. Interv Neuroradiol 20(5): 591-602.

7. Elnoamany H (2015). Percutaneous vertebroplasty: a first line treatment in traumatic non-osteoporotic vertebral compression fractures. Asian Spine J 9(2):178-184.
8. Milojkovic N, Homsi S (2014). Polymethylmethacrylate pulmonary embolism as a complication of percutaneous vertebroplasty in cancer patients. J Ark Med Soc 111(7):140-142.

9. Laredo JD, Hamze B (2004). Complications of percutaneous vertebroplasty and their prevention. Skeletal Radiology 33: 493 - 505.

10. Ledlie JT, Renfro M(2003). Balloon kyphoplasty: One-year outcomes in vertebral body height restoration, chronic pain and activity levels. $J$ Neurosurgery 98:36-42.

11. Gangi A, Guth S, Imbert JP, Marin H, Dietemann JL (2003). Percutaneous vertebroplasty: indications, technique, and results . Radiographics 23(2): e10.

12. John DB, Mary EJ, Joshua A, et al. (2013). Position statement on percutaneous vertebral augmentation: a consensus statement developed by the society of interventional radiology (SIR), american association of neurological surgeons (AANS) and the congress of neurological surgeons (CNS), american college of radiology (ACR), american society of neuroradiology (ASNR), american society of spine radiology (ASSR), canadian interventional radiology association (CIRA) and society of neurointerventional surgery (SNIS). J Vasc Interv Radiol 25 (2): 171 - 181. 
13. Streitparth F, Hartwig $T$, Walter $T$ (2013). MR guidance and thermometry of percutaneous laser disc decompression in open MRI: an initial clinical investigation. Eur Radiol 23(10): 2739-2746.

14. Singh V, Derby R (2006). Percutaneous lumbar disc decompression. Pain Physician 9(2): 139-146.

15. Baabor MG, Vazques PF, Sanchez JA (2011). Automated nucleotomy and nucleolysis with ozone. Acta Neurochir Suppl 108 : 97-101.

16. Cosma FA, Simonett L, Fabio de santis, et al. (2003). Minimally invasive oxygen-ozone therapy lumber disc herniation. AJNR 24: 996-1000.

17. Jana M, Srivastava DN, Sharma R, et al. (2011). Spectrum of magnetic resonance imaging findings in clinical glenohumeral instability. Indian J Radiol Imaging 21(2): 98106.

18. Jana M, Srivastava DN, Sharma R, et al. (2012). Magnetic resonance arthrography for assessing severity of glenohumeral labroligamentous lesions. J Orthop Surg (Hong Kong) 20(2): 230-235.

19. Pahwa S, Srivastava DN, Sharma R, Gamanagatti S, Kotwal PP, Sharma V (2014). Comparison of conventional MRI and MR arthrography in the evaluation of wrist ligament tears: a preliminary experience. Indian $J$ Radiol Imaging 24(3): 259-267.

20. Otjen J, Parnell SE, Menashe S, Thapa MM (2015). Ultrasound guided joint injections for MR arthrography in paediatric patients: how we do it. Pediatr Radiol 45(3): 308-316.

21. Ruiz Santiago F, Castellano Garcia Mdel M, Guzman Alvarez L, et al. (2011). Percutaneous treatment of bone tumours by radiofrequency thermal ablation. Eur J Radiol 77(1) :156-163.

22. Rajalakshmi P, Srivastava DN, Rastogi S, Julka PK, Bhatnagar S, Gamanagatti S (2012). Bipolar radiofrequency ablation of tibial chondroblastoma: a report of three cases. World JRadiol 4(7): 335-340.

23. Moraes VY, Lenza M, Tamaoki MJ, Faloppa F, Belloti JC (2014). Platelet-rich therapies for musculoskeletal soft tissue injuries. Cochrane Database Syst Rev. Apr 29;4:CD010071.

24. Von Wehren L, Blanke F, Todorov A, Heisterbach P, Saller J, Majewski $M$ (2015). The effect of subacromial injections of autologous conditioned plasma versus cortisone for the treatment of symptomatic partial rotator cuff tears. Knee Surg Sports Traumatol Arthrosc. 2015 May 28. 